\title{
Research on Enterprise Internal Control Construction in the Internet Era
}

\author{
Zhaohan Ding, Jing Su, Guanghui Li \\ XingTai University, Xingtai, 054000, China
}

\author{
Keywords: Internet era, Enterprise, Internal control
}

\begin{abstract}
The foundation of normal operation and management of the enterprise is internal control; the actual situation of the enterprise internal control will directly affect whether the enterprise's successful operation. Continuous rapid development of electronic data processing will bring great impact and economic benefits to enterprises, but also will affect the internal control system to a certain extent, and form new control requirements, impacting on the enterprise internal control to a great extent. In recent years, the rapid development of the Internet brings great challenges and opportunities to the enterprise internal control which applies computer information system. Therefore, we need to establish effective and reasonable enterprise internal computer control, guarantee to form the internal control mechanism based on the internet.
\end{abstract}

\section{Introduction}

In recent years, due to the continuous development of the Internet, big data, innovation of enterprise, and makes the enterprise and media have begun to gradually attaches great importance to the internal control mechanism, the age of the Internet, no matter what industry is inevitably affected by environmental degradation of the new technology and the impact, for enterprise internal control, need to face the customer and the staff, in the process of communication and exchanges, the development of enterprise at present are attaches great importance to the age of the Internet and the relationship between the internal control, but little attention because of the development of the Internet age to the effects of internal control to control the market environment and market environment risk, reform technology will greatly affect the degree of enterprise internal control construction, to promote enterprise's development and progress, this article mainly analyzes the enterprise internal control construction of the Internet era, studied the practical significance of the construction of internal control, the age of the Internet on the challenges and opportunities, the age of the Internet enterprise internal control problems and countermeasures of construction of internal control.

\section{Practical significance of enterprise internal control construction in internet era}

In the process of enterprise management is an important restriction and adjust the way is the internal control, from the start construction to gradually perfect the process of enterprise internal control will go through three stages, basically used internal check, establish a restriction mechanism, building control system. Enterprises in order to ensure the specified can be ordered the normal business activities and the design of accounting procedures and policy is the enterprise internal accounting control, the application of the basic function is to a certain extent, guarantee is truthful and accurate accounting information, and ensure the safety of the assets can ensure smooth implementing and executing enterprise internal rules and regulations and relevant national laws and regulations and restrictions within the enterprise economic activities, the enterprise internal audit and other related work, due to the highly consistent enterprise to maximize the value goal and the management goal, has gradually become an important part of enterprise internal control. Form a modern enterprise internal control system, improve internal management, is the actual demand of promoting economic benefit maximization ${ }^{[1]}$. The key part in the process of modern enterprise management is the internal control; to ensure normal operation of enterprises, establishing the modern enterprise internal control system, improve the management benefit of enterprise management has great significance. The most 
important thing at this stage, the reform of accounting system is reasonable information distortion problem, improve the enterprise internal control is to guarantee the normal operation.

\section{Challenges and opportunities for internal control in internet era}

\section{Challenges for traditional internal control in internet era}

The development of the Internet age, the will to a certain extent, brings to the enterprise department control challenges, can from the following several aspects to carry on the analysis, including internal audit reports timeliness, audit risk, auditors, audit services, etc.

First, the complication of the audit risk. Based on the age of the Internet's development and progress, and constantly change the previous way of internal control of accounting jobs, information system and virtual market environment to a certain extent affect the internal audit control, does not guarantee that can complete control, reduce the safety and reliability of the internal audit activity, increased the complexity of risk control.

Second, the impact on the traditional audit services. At present, the existence of Facebook's most influential Internet enterprise in the process of construction, in addition to have an IPO business, also can decrease the effectiveness of internal audit report, the high-speed development of network and information technology, more extensive began to expand the scope of the audit.

Third, the impact of internal performance evaluation way. Previous way of internal performance evaluation, more emphasis on cost, revenue, profits, along with the continuous development of the Internet, to a large extent changed the business model, leading enterprises are hard to enter the low-end market, therefore, to a large extent influence enterprise internal performance evaluation models, cannot use the traditional way to development of the Internet on the basis of internal control.

Fourth, increase the demand for internal auditors. Using artificial manual operating mode to design, according to the knowledge of audit and experience, with the continuous development of the Internet, not only needs the auditor have a certain professional knowledge, should also have a master of accounting information system, at present, or the internal environment and the lack of professional talents, make the internal control and the Internet there is a problem.

\section{Opportunities for internal control in internet era}

The important way of modern social development business activities is the Internet, basic core means is electronic technology and electronic, core business, enterprises can conform to the globalization, individualized, immaterialized, integration, network development, based on the development of the Internet, bring opportunities for internal control.

First, more extensive application of the internal control audit services, in the field of the materials and supplies for service in the field, due to the evolution of the Internet era, will largely improve audit services, audit service scope expanding.

Second, reduce the internal audit fees. Under the premise of development in the Internet age, the organic combination of the Internet and computer can automatically collect need audit information, can to a certain extent, reduce the audit information costs, reduce the audit in the process of waiting for the audit cost and search for the audit cost, save manpower, reduce consumption of resources within the enterprise.

Third, the modernization, diversification of audit measuring tool. With the development of the Internet age, the key technology is the information technology and modern equipment, need to fully understand and master advanced electronic tools and techniques, fully conform to the requirements of the market, continuously improve enterprise competitiveness. Electronic public system and electronic money, etc., for example, can increase the system efficiency appropriately, modernization and informatization measurement tools, can change the audit way, to a certain extent can guarantee enterprise audit internal financial situation at any time, maximum play a real role.

Fourth, increase the enterprise internal control report timeliness and accuracy, on the basis of the age of the Internet, can increase the degree of enterprise network, to shorten the time of formation of 
audit results and audit time, automation system, can at any time to master and follow up audit report, in addition, can also according to the manual audit approach, using the form of high automation, high intelligence, not only can increase the efficiency, also can improve the accuracy of audit, security can be quickly simple control.

Fifth, in the form of international audit market. Due to the continuous development of the Internet, on the basis of the economic system, increasing regionalization degree and scope of audit market, prompt development in the direction of nationalization. In ensuring that can meet the actual situation, on the basis of the development of internal control to establish a certain space ${ }^{[2]}$.

\section{Problems existing in enterprise internal control construction in internet era}

First, post setting. With the development of the Internet, the company began to merge or cancel the relevant functions of the enterprise, not compatible with the manual control of a number of business can be based on a person at the same time to complete the merger and re division of duties and responsibilities as well as job positions, and appropriate migration positions focus. For enterprise accounting, according to the different forms of accounting information to design accounting positions, reasonably divided into accounting information system management group, operation group, accounting group. On the basis of the Internet, the center of gravity from the traditional to the modern information system, such as changing job responsibilities and job positions, can enhance the cooperation and competition among enterprises.

Second, transaction authorization. The traditional methods of the formal authorization of the transaction are all sealed and signed, but with the development of the Internet, all transactions are embedded in the computer. Such authorization will be very few of the intervention manual, according to computer programs can be automatically carried out, so as to reduce the workload, increase the work efficiency, but in practical application, there will be a certain risk, because the enterprise internal financial has a certain confidentiality and openness, for the internal work, system accounting information personnel are set up the corresponding password. However, due to the different moral quality and working attitude of the operator, if the internal staff of the enterprise to steal passwords, change the authority, it will make a great impact on the internal control of enterprises.

Third, information security. On the basis of Internet and computer, we need to use electronic symbols to replace accounting data. If we cannot strictly control the internal data, we cannot get a certain decision, will form an issue that is not allowed to access or illegal access ${ }^{[3]}$.

\section{Countermeasures for enterprise internal control construction in internet era}

\section{Enhance enterprise internal information system security}

Application of enterprise information system, not only can improve the internal work efficiency, but also to a certain extent, increase the risk of enterprise management, in the enterprise local area network can reasonably check the data of enterprise management system, in the Internet can also query, but need a certain access license and valid password, at present, still cannot effectively solve the Internet Security problem. To ensure that the overall security of the enterprise internal information system, can cause criminals to find ways to change the enterprise data. Therefore, for the enterprise internal audit control management personnel put forward higher requirements, not only need to have certain business ability, but also need to have a modern processing mode, can guarantee accurate and reliable data information.

\section{Complete internal control system based on internet}

In the process of designing enterprise internal control system, it is likely to have a certain deficiencies, make the not timely and effective to prevent fraud or error, in the process of operation of internal control deviation and possible weaknesses not found error in time, the enterprise internal control system of information collection, analysis, sorting, evaluating main use is strong, the 
comprehensive information system, enterprise internal control system can transfer information appropriately, the analysis of the actual factors of the internal control defects, have certain specific improvement scheme is put forward, constantly optimize the behavior of the enterprise staff, stimulate the enthusiasm and motivation, improve and perfect internal control mechanism, guarantee has the maximum benefit of the enterprise value ${ }^{[4]}$.

\section{Establish effective internal audit system}

Internal audit is actually in the service sector, the organization form of independent supervision, inspection, evaluation mechanism, not only can make full and effective inspection and evaluation of internal check system, and also can ensure the integrity of the enterprise internal information, authenticity, legitimacy, supervision, inspection and evaluation of enterprise internal management norms and business performance and the safety of the assets. An important part of enterprise internal control is the internal audit, is not only an important part of accounting internal control, is also the important condition of supplementary audit. Enterprise established within a certain auditing department, need to keep clear internal actual responsibility and target, ensure that have certain independence, is on a matter of judgment and doubt.4. Improve risk prevention awareness and practices

In the process of enterprise internal control, the enterprise internal management level of risk is one of the most important measure of enterprise control standards. The bottom line is that the enterprise production and survival risk management, enterprise implementation of the internal risk management, not only belongs to the policy requirements, is also an important way to improve enterprise management and competition capability. At present, in the process of enterprise development, pay more and more attention to investors and capital markets, and the internal control of the actual level to a certain extent, affect the embodiment in the capital market financing ability, can also affect the sustainable healthy development of the enterprise. Enterprise internal control is not to reduce the risk, is not to eliminate risk, need reasonable control of enterprise risk within a certain scope, provide safeguard for the enterprise to achieve management goals. Organic combination of enterprise external management environment and its own actual situation, determine the risk of enterprise internal control point and control link, especially the need to manage and control has a high risk of control points, to avoid financial risk. Key point is in the process of risk control management contract, need appropriate specific management contract, enterprise management of related department responsibility, operation methods and management processes, and clear the obligations and responsibilities of each department. Ensure that other departments related to contract management department can smooth implementation and execution censorship, as long as it is related to manage money, calculate the price, investment financing some of the terms and conditions, all need through the enterprise relevant financial, planners, unit leader, in charge of the leadership signature verification, in the production and business operation, financing, follow-up supervision source implementation of standard management, reduce management irregularities in the contract, resulting in a contract dispute ${ }^{[5]}$.

\section{Conclusions}

All in all, the enterprise internal control in the Internet era is constantly changing the control form, control content, control technology, based on the development of the Internet, the organic combination of the actual market specifications and needs, good internal control in the Internet situation, the challenges and opportunities, improve the prevention and control of the risk of internal control for enterprises to establish a good environment.

\section{Acknowledgments}

This paper is a 2015 social sciences fund project of Hebei Province, Name: Research on enterprise internal control adaptability in "Internet +" era. Project approval No.: HB15YJ009 


\section{References}

[1] Chen Peng. Enterprise internal control and audit in internet finance environment. China E-commerce, 2014(10):195.

[2] Liu Jiahuan. Some thought of enterprise internal control under the wave of big data and internet finance . Time finance (Mid), 2015(2):57-58.

[3] Zhou Ying. Discussion on enterprise internal control under impact of internet finance . China Business Update, 2014(7):89-89.

[4] Ma Junhong. Research on enterprise internal control construction in the Internet era . China E-commerce, 2012(21):50-50.

[5] Li Chuyu. On financial innovation and enterprise internal control system construction .Small and medium enterprises management and technology, 2014(9):36-37. 